\title{
Hubungan Perilaku Pemeliharaan Kebersihan dengan Status Gingiva pada Pengguna Gigi Tiruan Sebagian Lepasan
}

\author{
${ }^{1}$ Puspitasari Baba \\ ${ }^{2}$ Vonny N. S. Wowor \\ ${ }^{3}$ Lydia Tendean
}

\author{
${ }^{1}$ Program Studi Pendidikan Dokter Gigi Fakultas Kedokteran \\ ${ }^{2}$ Bagian Prostodontia Program Studi Pendidikan Dokter Gigi Fakultas Kedokteran \\ ${ }^{3}$ Bagian Biologi Fakultas Kedokteran \\ Universitas Sam Ratulangi Manado \\ Email: puspitababa@yahoo.com
}

\begin{abstract}
Denture hygiene behavior is an important factor in the success of denture treatment because it has a close relationship with attitude, knowledge, and action of denture wearers. Improper maintance of denture hygiene can cause problems to oral health, especially in removable denture wearers. Gingiva is often used as an indicator of periodontal diseases. This study was aimed to obtain the denture hygiene behavior, gingival status, and the relationship between these two conditions among partial removal acrylic-based denture wearers at Wawalintoan, West Tondano. This was a descriptive analytical study with a cross-sectional design performed on 68 respondents wearing partial removal acrylic-based dentures obtained by using purposive sampling technique. Data were collected through questionnaire of denture hygiene behavior and examination of gingival index. The results showed that the respondents had good knowledge, attitude, and action of dental hygiene with an average score of $453(66.6 \%)$. The gingival status was categorized as mild in 39 people $(57.4 \%)$. The relationship between hygiene maintance and gingival status of the respondents analyzed by using the chi-square test obtained a $P$-value of $0.000<0.05$. Conclusion: There was a significant relationship between denture hygiene behavior and gingival status of partial removable denture wearers.
\end{abstract}

Keywords: hygiene maintance behavior, gingival status, partial removable denture

\begin{abstract}
Abstrak: Perilaku pemeliharaan kebersihan gigi tiruan merupakan faktor penting dalam keberhasilan perawatan gigi tiruan karena berhubungan erat dengan pengetahuan, sikap, dan tindakan pengguna gigi tiruan. Pemeliharaan kebersihan gigi tiruan yang kurang baik dapat menimbulkan masalah bagi kesehatan gigi dan mulut terutama pada pengguna gigi tiruan lepasan. Gingiva sering dijadikan sebagai indikator pada penyakit jaringan periodontal. Penelitian ini bertujuan untuk mengetahui gambaran perilaku pemeliharaan kebersihan, status kesehatan gingiva pada pemakai gigi tiruan, dan hubungan perilaku pemeliharaan kebersihan dengan status gingiva pada pengguna gigi tiruan sebagian lepasan (GTSL) berbasis akrilik. Jenis penelitian ialah deskriptif analitik dengan desain potong lintang yang dilakukan pada 68 responden pengguna GTSL berbasis akrilik di Kelurahan Wawalintoan, Kecamatan Tondano Barat yang dipilih menggunakan teknik purposive sampling. Pengumpulan data dilakukan melalui kuesioner perilaku pemeliharaan kebersihan dan pemeriksaan indeks gingiva. Hasil penelitian menunjukkan bahwa dari pemeliharaan kebersihan gigi, responden memiliki pengetahuan, sikap, dan tindakan yang tergolong baik dengan skor rerata $453(66,6 \%)$. Status gingiva responden tergolong kategori ringan sebanyak 39 orang $(57,4 \%)$. Hasil uji chi-square terhadap hubungan antara pemeliharaan kebersihan dan status gingiva pengguna GTSL mendapatkan $P=0,000 \leq 0,05$. Simpulan: Terdapat hubungan bermakna antara perilaku pemeliharaan kebersihan dan status gingiva pada pengguna GTSL.
\end{abstract}

Kata kunci: perilaku pemeliharaan kebersihan, status gingiva, GTSL 
Gigi tiruan lepasan merupakan gigi tiruan yang menggantikan gigi yang hilang dari jaringan di sekitarnya dalam lengkung rahang dan bisa dilepas dari rongga mulut serta dipasang kembali oleh pasien. Gigi tiruan lepasan secara garis besar dapat dibagi menjadi gigi tiruan sebagian lepasan (partial denture) dan gigi tiruan penuh (full denture atau complete denture). Bahan basis gigi tiruan lepasan dapat terbuat dari resin akrilik, logam dan nilon termoplastik atau valplast. Salah satu keuntungan dari perawatan gigi tiruan lepasan adalah dapat dilepas dari rongga mulut sehingga pasien dapat dengan mudah membersihkan gigi tiruan mereka untuk memelihara kesehatan rongga mulutnya. ${ }^{1}$

Perilaku memelihara kebersihan gigi tiruan merupakan faktor penting dalam keberhasilan perawatan gigi tiruan. Perilaku memelihara kebersihan gigi tiruan mempunyai hubungan erat dengan pengetahuan, sikap, dan tindakan masyarakat dalam menggunakan gigi tiruan. Hal ini disebabkan karena pengetahuan, sikap, dan tindakan merupakan aspek penting dalam penilaian perilaku seseorang, sehingga perilaku sehari-hari dalam memelihara kebersihan gigi tiruan sebagian lepasan (GTSL) dapat diukur melalui ketiga aspek tersebut. Pengetahuan yang baik tentang cara memelihara kebersihan gigi tiruan akan menghasilkan sikap positif terhadap pemeliharaan kebersihan gigi tiruan, sehingga memberikan pengaruh yang baik terhadap kesehatan gigi dan mulut yang diwujudkan melalui tindakan. ${ }^{2}$

Masalah gingivitis erat kaitannya dengan kebersihan gigi tiruan. Perilaku dalam menjaga kebersihan gigi tiruan akan mempengaruhi kondisi kesehatan gigi dan mulut. Kebersihan mulut dan gigi yang kurang terjaga antara lain dapat berdampak pada terjadinya gingivitis. ${ }^{3}$ Gingivitis adalah infeksi bakteri campuran yang mengakibatkan peradangan dan kerusakan reversibel pada jaringan gingiva tanpa hilangnya perlekatan jaringan ikat. Gingivitis dapat ditemukan pada segala usia dan terjadi karena akumulasi plak. Diagnosis gingivitis ditentukan berdasar- kan perdarahan, perubahan warna, konsistensi dan kontur gingiva. ${ }^{4,5}$

Kelurahan Wawalintoan merupakan salah satu kelurahan yang terletak di Kecamatan Tondano Barat dengan jumlah populasi 3.119 jiwa. Berdasarkan survei awal, cukup banyak masyarakat di Kelurahan Wawalintoan yang memakai GTSL. Penelitian ini bertujuan untuk mengetahui hubungan perilaku pemeliharaan kebersihan dan status gingiva pada pengguna GTSL di Kelurahan Wawalintoan

\section{BAHAN DAN METODE PENELITIAN}

Jrni penelitian ini ialah deskriptif analitik dengan desain potong lintang. Penelitian dilakukan di Kelurahan Wawalintoan Kecamatan Tondano Barat Kabupaten Minahasa pada bulan Agustus 2017. Populasi penelitian ini ialah pengguna GTSL berbasis akrilik di Kelurahan Wawalintoan yang berdasarkan hasil perhitungan prevalensi berjumlah 221 orang. Besar sampel ditentukan dengan menggunakan rumus Slovin dan mendapatkan jumlah sampel sebesar 68 responden.

Pemeriksaan indeks gingiva dilakukan di sulkus gingiva pada rahang atas. Yang diperiksa yaitu gigi M1 kanan, I2 kiri, dan P1 kiri. Pada rahang bawah yang diperiksa yaitu gigi M1 kiri, I1 kanan dan P1 kanan. Penghitungan indeks gingiva menggunakan indeks gingiva menurut Loe and Sillness. Probe periodontal digunakan untuk mengukur sulkus gingiva dan kedalaman poket.

Perilaku pemeliharan kebersihan diukur menggunakan kuesioner yang terdiri dari tiga bagian yaitu perilaku, sikap, dan tindakan. Skala yang digunakan yaitu skala Guttman. Alternatif jawaban dari kuesioner yang diberikan yaitu tahu, setuju, dan ya diberi skor 2 dan jawaban tidak tahu, tidak setuju dan tidak diberi skor 1 .

Permohonan izin penelitian disampaikan ke kantor kepala desa di Kelurahan Wawalintoan Kecamatan Tondano Barat. Setelah mendapat izin, kemudian meminta kesediaan masyarakat untuk menandatangani informed concent dan mengisi kuesioner.

Analisis univariat data berdasarkan 
persentase disajikan dalam bentuk tabel untuk melihat status gingiva dari responden sedangkan analisis bivariat untuk menguji hubungan variabel perilaku pemeliharaan kebersihan dan status gingiva pada pengguna GTSL dengan menggunakan uji Chi-square.

\section{HASIL PENELITIAN}

Hasil penelitian diperoleh melalui pemeriksaan status gingiva, dan berdasarkan data jenis kelamin, usia, dan pekerjaan.

Tabel 1 memperlihatkan bahwa responden perempuan $(54,4 \%)$ lebih banyak daripada responden laki-laki $(45,6 \%)$. Tabel 2 menunjukkan bahwa respon-den terbanyak berusia 41-50 tahun (30,9\%), dan urutan kedua berusia 31-40 tahun (26,5\%). Tabel 3 memaparkan bahwa pekerjaan responden yang terbanyak ialah PNS $(29,4 \%)$. Tabel 4 menunjukkan bahwa indeks gingiva terbanyak terdapat pada kategori ringan $(57,4 \%)$.

Tabel 1. Distribusi responden berdasarkan jenis kelamin

\begin{tabular}{ccc}
\hline Jenis kelamin & (n) & (\%) \\
\hline Laki-Laki & 31 & 45,6 \\
Perempuan & 37 & 54,4 \\
Total & 68 & 100 \\
\hline
\end{tabular}

Tabel 2. Distribusi responden berdasarkan usia

\begin{tabular}{ccc}
\hline Usia $($ Tahun) & $(\mathbf{n})$ & $\mathbf{( \% )}$ \\
\hline 12-20 tahun & 5 & 7,4 \\
21-30 tahun & 15 & 22,0 \\
31-40 tahun & 18 & 26,5 \\
41-50 tahun & 21 & 30,9 \\
51-60 tahun & 9 & 13,2 \\
Total & 68 & 100 \\
\hline
\end{tabular}

Tabel 3. Distribusi responden berdasarkan pekerjaan.

\begin{tabular}{ccc}
\hline Pekerjaan & (n) & $(\mathbf{\% )}$ \\
\hline PNS & 20 & 29,4 \\
Petani & 9 & 13,2 \\
Wiraswasta & 13 & 19,1 \\
Swasta & 10 & 14,7 \\
Tidak Bekerja & 16 & 23,6 \\
Total & 68 & 100 \\
\hline
\end{tabular}

Tabel 4. Distribusi karateristik status gingiva pemakai GTSL akrilik

\begin{tabular}{ccc}
\hline Indeks gingiva & $(\mathbf{n})$ & $\mathbf{( \% )}$ \\
\hline Sehat & 7 & 10,3 \\
Ringan & 39 & 57,4 \\
Sedang & 16 & 23,5 \\
Berat & 6 & 8,8 \\
Total & 68 & 100 \\
\hline
\end{tabular}

Tabel 5-7 menampilkan hasil kuesioner perilaku pemeliharan kebersihan GTSL.

Tabel 5. Distribusi hasil penilaian pengetahuan responden pengguna GTSL berbasis akrilik di Wawalintoan Kecamatan Tondano Barat

\begin{tabular}{|c|c|c|c|c|}
\hline No & Pertanyaan & $\begin{array}{c}\text { Tahu } \\
\text { (n) }\end{array}$ & $\begin{array}{l}\text { Tidak tahu } \\
\text { (n) }\end{array}$ & $\begin{array}{c}\text { Total skor } \\
\text { penilaian }\end{array}$ \\
\hline 1 & $\begin{array}{l}\text { Tahukah anda bahwa pengguna gigi tiruan berdampak buruk } \\
\text { pada kebersihan rongga mulut? }\end{array}$ & 24 & 44 & 92 \\
\hline 2 & $\begin{array}{l}\text { Tahukah anda bahwa gigi tiruan harus dilepas pada malam hari } \\
\text { sewaktu akan tidur untuk mengurangi kemungkinan patah, } \\
\text { terutama bagi pengguna yang memiliki kebiasaan jelek seperti } \\
\text { bruxism (gerinding gigi), dan agar gigi tiruan tetap terjaga? }\end{array}$ & 20 & 48 & 88 \\
\hline 3 & $\begin{array}{l}\text { Tahukah anda bila gigi tiruan yang dilepas dan tidak digunakan } \\
\text { pada malam hari bila tidak direndam dalam air dapat } \\
\text { mengakibatkan gigi mengerut sehingga akan menyebabkan gigi } \\
\text { tiruan tidak pas pada mulut pengguna? }\end{array}$ & 12 & 56 & 80 \\
\hline 4 & $\begin{array}{l}\text { Tahukah anda bahwa membersishkan gigi asli atau gigi sisa } \\
\text { dan jaringan lunak mulut (langit-langit, lidah, dan gusi) dapat } \\
\text { mencegah timbulnya jamur dan bau mulut? }\end{array}$ & 25 & 43 & 93 \\
\hline \multirow[t]{2}{*}{5} & $\begin{array}{l}\text { Tahukah anda bahwa perlu dilakukan kontrol ke dokter gigi } \\
\text { setelah pemasangan gigi tiruan agar kesehatan gigi dan mulut } \\
\text { pengguna gigi tiruan tetap terjaga? }\end{array}$ & 20 & 48 & 88 \\
\hline & Total skor & & & 441 \\
\hline
\end{tabular}


Baba, Wowor, Tendean: Hubungan perilaku pemeliharaan kebersihan dengan ...

Tabel 6. Distribusi hasil penilaian sikap responden pengguna GTSL berbasis akrilik di Wawalintoan Kecamatan Tondano Barat

\begin{tabular}{clccc}
\hline No & \multicolumn{1}{c}{ Pertanyaan } & $\begin{array}{c}\text { Setuju } \\
(\mathbf{n})\end{array}$ & $\begin{array}{c}\text { Tidak setuju } \\
\text { (n) }\end{array}$ & $\begin{array}{c}\text { Total skor } \\
\text { penilaian }\end{array}$ \\
\hline 1 & $\begin{array}{l}\text { Setujukah anda bahwa gigi tiruan perlu dijaga kebersihannya? } \\
2\end{array}$ & 50 & 18 & 118 \\
Setujukah anda bahwa gigi tiruan harus dilepas pada malam & 20 & 48 & 88 \\
hari sewaktu akan tidur? & $\begin{array}{l}\text { Setujukah anda bahwa gigi tiruan yang dilepas dan tidak } \\
\text { dipakai pada malam hari harus direndam dalam air? }\end{array}$ & 15 & 53 & 83 \\
4 & $\begin{array}{l}\text { Setujukah anda bahwa gigi asli atau gigi sisa dan jaringan } \\
\text { lunak mulut (langit-langit, lidah, dan gusi) juga perlu dijaga } \\
\text { kebersihannya? }\end{array}$ & 25 & 43 & 93 \\
5 & $\begin{array}{l}\text { Setujukah anda bahwa perlu dilakukan kontrol ke dokter gigi } \\
\text { setelah pemasangan gigi tiruan? } \\
\text { Total skor }\end{array}$ & 29 & 39 & 97 \\
\hline
\end{tabular}

Tabel 7. Distribusi hasil penilaian tindakan responden pengguna GTSL berbasis akrilik di Wawalintoan Kecamatan Tondano Barat.

\begin{tabular}{clccc}
\hline No & \multicolumn{1}{c}{ Pertanyaan } & $\begin{array}{c}\text { Ya } \\
(\mathbf{n})\end{array}$ & $\begin{array}{c}\text { Tidak } \\
(\mathbf{n})\end{array}$ & $\begin{array}{c}\text { Total skor } \\
\text { penilaian }\end{array}$ \\
\hline 1 & $\begin{array}{l}\text { Apakah anda membersihkan gigi tiruan setiap selesai } \\
\text { makan? }\end{array}$ & 33 & 35 & 101 \\
2 & $\begin{array}{l}\text { Apakah anda melepas gigi tiruan pada saat akan tidur } \\
\text { malam? }\end{array}$ & 13 & 55 & 81 \\
3 & $\begin{array}{l}\text { Apakah anda merendam gigi tiruan dalam air saat gigi } \\
\text { tiruan tersebut dilepas dan tidak dipakai? }\end{array}$ & 14 & 54 & 82 \\
$\begin{array}{l}\text { Apakah anda membersihkan gigi asli atau gigi sisa dan } \\
\text { jaringan lunak mulut (langit-langit, lidah, dan gusi)? } \\
\text { Apakah anda melakukan kontrol kepada dokter gigi } \\
\text { setelah pemasangan gigi tiruan? } \\
\text { Total skor }\end{array}$ & 21 & 47 & 89 \\
$\quad$ & 49 & 87 \\
\hline
\end{tabular}

Tabel 8. Distribusi hasil penilaian perilaku memelihara kebersihan GTSL berbasis akrilik pada masyarakat Kelurahan Wawalintoan Kecamatan Tondano Barat

\begin{tabular}{ccc}
\hline No & Aspek perilaku & Skor \\
\hline 1 & Pengetahuan & 441 \\
2 & Sikap & 479 \\
3 & Tindakan & 440 \\
& Skor rerata & 453 \\
\hline
\end{tabular}

Berdasarkan hasil uji korelasi menggunakan chi-square test, didapatkan hubungan perilaku pemeliharaan kebersihan dengan status gingiva pada pengguna GTSL untuk pengetahuan yaitu $P=0,011 \leq 0,05$; sikap $P=0,000 \leq 0,05$; dan tindakan $P=0,000 \leq 0,05$.

Tabel 9, 10, dan 11 memaparkan hubungan antara pengetahuan, sikap dan tindakan dengan status gingiva

Tabel 9. Hubungan pengetahuan dan status gingiva

\begin{tabular}{|c|c|c|c|c|c|c|c|c|c|c|}
\hline \multirow{3}{*}{$\begin{array}{l}\text { Kategori } \\
\text { pengetahuan }\end{array}$} & \multicolumn{8}{|c|}{ Status gingiva } & \multirow{2}{*}{\multicolumn{2}{|c|}{ Total }} \\
\hline & \multicolumn{2}{|c|}{ Sehat } & \multicolumn{2}{|c|}{ Ringan } & \multicolumn{2}{|c|}{ Sedang } & \multicolumn{2}{|c|}{ Berat } & & \\
\hline & $\mathrm{n}$ & $\%$ & $\mathrm{n}$ & $\%$ & $\mathrm{n}$ & $\%$ & $\mathrm{n}$ & $\%$ & $\mathrm{n}$ & $\%$ \\
\hline Kurang & 0 & 0 & 9 & 13,2 & 5 & 7,4 & 3 & 4,4 & 17 & 25,0 \\
\hline Baik & 7 & 10,3 & 30 & 44,1 & 11 & 16,2 & 3 & 4,4 & 51 & 75 \\
\hline Total & 7 & 10,3 & 39 & 57,3 & 16 & 23,6 & 6 & 8,8 & 68 & 100 \\
\hline
\end{tabular}


Tabel 10. Hubungan sikap dengan status gingiva

\begin{tabular}{|c|c|c|c|c|c|c|c|c|c|c|}
\hline \multirow{3}{*}{ Kategori sikap } & \multicolumn{8}{|c|}{ Status gingiva } & \multirow{2}{*}{\multicolumn{2}{|c|}{ Total }} \\
\hline & \multicolumn{2}{|c|}{ Sehat } & \multicolumn{2}{|c|}{ Ringan } & \multicolumn{2}{|c|}{ Sedang } & \multicolumn{2}{|c|}{ Berat } & & \\
\hline & $\mathrm{n}$ & $\%$ & $\mathrm{n}$ & $\%$ & $\mathrm{n}$ & $\%$ & $\mathrm{n}$ & $\%$ & $\mathrm{n}$ & $\%$ \\
\hline Baik & 7 & 10,3 & 8 & 11,8 & 1 & 1,5 & 1 & 1,5 & 17 & 25,0 \\
\hline Kurang baik & 0 & 0,0 & 31 & 46,6 & 15 & 22,1 & 5 & 7,4 & 51 & 75,0 \\
\hline Total & 7 & 10,3 & 39 & 57,4 & 16 & 23,5 & 6 & 8,8 & 68 & 100 \\
\hline
\end{tabular}

Tabel 11. Hubungan tindakan dengan status gingiva.

\begin{tabular}{|c|c|c|c|c|c|c|c|c|c|c|}
\hline \multirow{3}{*}{ Kategori tindakan } & \multicolumn{8}{|c|}{ Status gingiva } & & \\
\hline & \multicolumn{2}{|c|}{ Sehat } & \multicolumn{2}{|c|}{ Ringan } & \multicolumn{2}{|c|}{ Sedang } & \multicolumn{2}{|c|}{ Berat } & \multicolumn{2}{|c|}{ Total } \\
\hline & $\mathrm{n}$ & $\%$ & $\mathrm{n}$ & $\%$ & $\mathrm{n}$ & $\%$ & $\mathrm{n}$ & $\%$ & $\mathrm{n}$ & $\%$ \\
\hline Baik & 7 & 10,3 & 10 & 14,7 & 3 & 4,4 & 0 & 0,0 & 20 & 29,4 \\
\hline Kurang baik & 0 & 0,0 & 29 & 42,7 & 13 & 19,1 & 6 & 8,8 & 48 & 70,6 \\
\hline Total & 7 & 10,3 & 39 & 57,3 & 16 & 23,5 & 6 & 7,4 & 68 & 100 \\
\hline
\end{tabular}

\section{BAHASAN}

Telah dilakukan penelitian mengenai hubungan perilaku pemeliharaan kebersihan GTSL dan status gingiva pada pengguna GTSL di Kelurahan Wawalintoan Kecamatan Tondano Barat yang berjumlah 68 responden terdiri dari 37 orang laki-laki $(45,6 \%)$ dan 31 orang perempuan $(54,4 \%)$. Seluruh masyarakat yang memenuhi kriteria diberikan kuesioner perilaku pemeliharaan kebersihan yang terdiri dari pengetahuan, sikap dan tindakan kemudian dilakukan pemeriksaan indeks gingiva.

Pada penelitian ini masalah gingiva paling banyak ditemui pada masyarakat yang berusia $41-50$ tahun $(30,9 \%)$, disusul oleh usia 31-40 tahun (26,5\%), usia 21-30 tahun $(22,0 \%)$, usia 51-60 tahun $(13,2 \%)$, dan paling sedikit yang berusia 12-20 tahun $(7,4 \%)$. Sebagian besar masyarakat memiliki pekerjaan sebagai PNS $(29,4 \%)$, diikuti yang tidak bekerja $(23,6 \%)$, wiraswasta $(19,1 \%)$, swasta $(14,7 \%)$, dan terendah sebagai siswa $(3,0 \%)$.

Berdasarkan hasil pemeriksaan indeks gingiva menurut Loe dan Silness, didapatkan bahwa hampir seluruh responden mengalami peradangan ringan, namun terdapat 7 responden yang memiliki gingiva sehat.

Perilaku memelihara kebersihan GTSL berbasis akrilik pada masyarakat Kelurahan Wawalintoan Kecamatan Tondano Barat dinilai berdasarkan tiga aspek yaitu pengetahuan, sikap, dan tindakan.

Hasil yang didapatkan pada aspek pengetahuan, pengguna GTSL berbasis akrilik di Kelurahan Wawalintoan memliki pengetahuan tergolong dalam kategori baik. Pada penilaian pengetahuan, pertanyaan pertama tentang dampak buruk pemakaian gigi tiruan terhadap kebersihan rongga mulut memperoleh hasil 24 responden yang tahu dan 44 responden yang tidak tahu. Pertanyaan kedua yaitu bahwa melepas gigi tiruan pada malam hari sewaktu akan tidur dapat mengurangi kemungkinan patah, terutama bagi yang memiliki kebiasaan jelek seperti bruxism (gerinding gigi) pada saat tidur mendapatkan 20 responden tahu dan 48 responden tidak tahu. Pertanyaan ketiga yaitu gigi tiruan yang dilepas dan tidak digunakan pada malam hari bila tidak direndam dalam air dapat mengakibatkan gigi mengerut sehingga akan menyebabkan gigi tiruan tidak pas pada mulut pengguna mendapatkan 12 responden tahu dan 56 responden tidak tahu. Pertanyaan keempat yaitu membersihkan gigi asli atau gigi sisa dan jaringan lunak mulut (langit-langit, lidah, dan gusi) dapat mencegah timbulnya jamur dan bau mulut mendapatkan 25 responden tahu dan 43 responden tidak 
tahu. Pertanyaan kelima yaitu perlu dilakukan kontrol ke dokter gigi setelah pemasangan gigi tiruan agar kesehatan gigi dan mulut pengguna gigi tiruan tetap terjaga mendapatkan 20 responden tahu dan 48 responden ridak tahu.

Kelima hasil pertanyaan ini menunjukkan bahwa mayoritas pengguna GTSL berbasis akrilik di Kelurahan Wawalintoan menggunakan gigi tiruan hanya sekedar menggunakan saja tanpa mengetahui dampak penggunaan gigi tiruan seperti memburuknya kebersihan mulut, meningkatnya akumulasi plak, bau mulut, karies, gingivitis, xerostomia, kandisiasis, dan penyakit periodontal. ${ }^{4,5}$ Hasil penelitian ini selaras dengan yang dilakukan oleh Titjo $^{6}$ di Kelurahan Bahu pada tahun 2013, yang menyatakan bahwa mayoritas pengguna gigi tiruan lepasan menggunakan gigi tiruan hanya sekedar menggunakan tanpa mengetahui dampak, fungsi, dan manfaat dari pemakaian gigi tiruan.

Ditinjau dari aspek sikap didapatkan bahwa sikap masyarakat dalam memelihara GTSL berbasis akrilik di Kelurahan Wawalintoan termasuk dalam kategori baik. Sebanyak 50 responden setuju bahwa gigi tiruan perlu dijaga kebersihannya sedangkan 20 responden yang tidak setuju. Sebanyak 20 responden setuju gigi tiruan dilepas pada malam hari sebelum tidur sedangkan 48 responden tidak setuju. Sebanyak 15 responden setuju gigi tiruan dilepas pada malam hari dan harus direndam dalam air sedangkan 53 responden tidak setuju. Terdapat 25 responden setuju gigi asli atau gigi sisa dan jaringan lunak mulut (langit-langit, lidah, dan gusi) juga perlu dijaga kebersihannya sedangkan 43 responden tidak setuju. Sebanyak 29 responden setuju perlu dilakukan kontrol ke dokter gigi setelah pemasangan gigi tiruan sedangkan 39 responden tidak setuju.

Hal ini disebabkan karena kurangnya pemahaman responden tentang manfaat dan tujuan dari pemeliharaan gigi tiruan. Sebagian responden hanya mendengar dari lingkungan sekitar tentang bahwa melepas gigi tiruan pada malam hari saat akan tidur dan harus direndam dalam air, namun tidak mengetahui bahwa gigi tiruan yang dilepas pada malam hari dan di rendam dalam air bertujuan untuk mengurangi kemungkinan patah terutama pada pengguna yang memiliki kebiasaan buruk saat tidur seperti bruxism (gerinding gigi), dan agar gigi tiruan tidak mengalami pengerutan yang dapat menyebabkan gigi tiruan tidak pas dimulut saat dipakai. ${ }^{6}$

Sikap responden dalam memelihara kebersihan gigi asli yang masih tersisa serta jaringan lunak mulut hanya sedikit. Hal ini disebabkan karena layanan kesehatan khususnya pembuatan gigi tiruan cukup menyita waktu dan membutuhkan biaya yang tidak sedikit bila berobat dan melakukan kontrol ke dokter gigi. ${ }^{7}$

Tindakan atau perbuatan nyata merupakan wujud dari aspek pengetahuan dan sikap. Hasil penelitian yang didapatkan dari aspek tindakan pada masyarakat Kelurahan Wawalintoan tergolong pada kategori baik. Sebanyak 33 responden membersihkan gigi tiruan setelah selesai makan sedangkan 35 responden tidak melakukannya. Sebanyak 13 responden melepas gigi tiruan pada saat akan tidur malam sedangkan 55 responden tidak melakukannya. Hanya 14 responden merendam gigi tiruan saat tidak digunakan sedangkan 54 responden tidak melakukannya. Hasil sejalan diperoleh pada penelitian yang dilakukan oleh Peraconi et al. ${ }^{6}$ di Universitas Sao Paolo Brasil yang menunjukkan bahwa $58,49 \%$ responden tidur menggunakan gigi tiruan. ${ }^{8}$ Kemudian 21 responden setuju membersihkan gigi asli atau gigi sisa dan jaringan lunak mulut (langit-langit, lidah, dan gusi) sedangkan 47 responden tidak melakukannya, 19 responden melakukan kontrol ke dokter gigi setelah pemasangan gigi tiruan sedangkan 49 responden tidak melakukannya.

Hasil penilaian perilaku pemeliharaan kebersihan GTSL berbasis akrilik pada masyarakat Kelurahan Wawalintoan Kecamatan Tondano Barat yang terdiri dari pengetahuan, sikap dan tindakan memperoleh skor rerata yaitu 453 .

Berdasarkan uji korelasi menggunakan chi-square test, hubungan perilaku pemeliharaan kebersihan dengan status gingiva 
pada pemakai gigi tiruan sebagian lepasan diperoleh hasil pengetahuan $P=0,011$ $\leq 0,05$; sikap $P=0,000 \leq 0,05$; dan tindakan $P=0,000 \leq 0,05$, sehingga dapat disimpulkan terdapat hubungan bermakna antara perilaku pemeliharaan kebersihan dengan status gingiva pada pengguna GTSL.

Hubungan berdasarkan pengetahuan menunjukkan bahwa terdapat 9 responden $(13,2 \%)$ berpengetahuan kurang dengan indeks gingiva ringan; sedang berjumlah 5 responden $(7,4 \%)$; dan berat berjumlah 3 responden $(4,4 \%)$. Responden yang berpengetahuan baik dengan indeks gingiva sehat berjumlah 7 responden $(10,3 \%)$; ringan berjumlah 30 responden $(44,1 \%)$; sedang berjumlah 11 responden $(16,2 \%)$; dan berat berjumlah 3 responden $(4,4 \%)$ (Tabel 9).

Hubungan berdasarkan sikap menunjukkan bahwa terdapat 7 responden $(10,3 \%)$ yang memiliki sikap positif dengan indeks gingiva sehat; ringan berjumlah 8 responden $(11,8 \%)$; sedang berjumlah 1 responden $(1,5 \%)$; dan berat berjumlah 1 responden (1,5\%) (Tabel 10). Responden yang bersikap negatif dengan indeks gingiva ringan berjumlah 31 responden $(46,6 \%)$ sedang berjumlah 15 responden $(22,1 \%)$; dan berat berjumlah 5 responden $(7,4 \%)$.

Hubungan berdasarkan tindakan menunjukkan bahwa terdapat 7 responden $(10,3 \%)$ yang memiliki perilaku positif dengan indeks gingiva sehat; ringan berjumlah 10 responden $(14,7 \%)$; dan sedang berjumlah 3 responden $(4,4 \%)$. Responden yang bersikap negatif dengan indeks gingiva ringan berjumlah 29 responden $(42,7 \%)$; sedang berjumlah 13 responden $(19,1 \%)$; dan berat berjumlah 6 responden $(8,8 \%)$ (Tabel 11).

\section{SIMPULAN}

Berdasarkan hasil penelitian ini dapat disimpulkan bahwa terdapat hubungan bermakna antara perilaku pemeliharaan kebersihan gigi tiruan dan status gingiva pada pengguna GTSL di Kelurahan Wawalintoan Kecamatan Tondano Barat.

\section{SARAN}

Diharapkan bagi institusi pemerintah dalam hal ini Dinas Kesehatan dan puskesmas untuk melakukan penyuluhan maupun sosialisasi kepada masyarakat tentang pentingnya kesehatan gigi dan mulut para pengguna GTSL.

Diharapkan hasil penelitian ini dapat memberikan informasi kepada masyarakat agar dapat lebih menjaga kebersihan gigi dan mulut.

\section{DAFTAR PUSTAKA}

1. Sipayung BI. Kebiasaan memelihara kebersihan gigi tiruan pada masyarakat pemakai gigi tiruan sebagian lepasan di Kelurahan Tanjung Rejo Kecamatan Medan Sunggal [Skripsi]. Medan: FKG USU; 2012.

2. Rahmayani L. Perilaku pemakaian gigi tiruan terhadap pemeliharaan kebersihan gigi tiruan lepasan. Jurnal PDGI. 2013;62(3):83-8.

3. Hartati, Rusmini, Waluyo. Analisis faktorfaktor yang berhubungan dengan kejadian gingivitis pada ibu hamil di wilayah kerja Puskesmas Talang Tegal. Jurnal Ilmiah Keperawatan. 2011;7(3):170-5.

4. Langlais RP, Miler CS, Nield-Gehrig JS, Atlas Berwarna Lesi Mulut yang Sering Ditemukan (4th ed). Jakarta: EGC, 2014; p. 84.

5. Silva BCM, de Sousa AA, de Magalhaes MA, Andre M, Brito E, Dias $R$. Candida albicans in patients with oronasal communication and obtu-rator prostheses. 2009;20(4):336-440.

6. Titjo OC. Perilaku masyarakat pengguna gigi tiruan lepasan di kelurahan Bahu [Skripsi]. Manado: Fakultas Kedokteran Program Studi Kedokteran Gigi Universitas Sam Ratulangi; 2013.

7. Lumonon TO, Wowor VNS, Soewantoro JS. Faktor determinan perilaku masyarakat dalam pemanfaatan jasa tukang gigi di Desa Treman Kecamatan Kauditan. eG. 2014;2(1).

8. Peracini A, de Andrade IM, Paranhos HdFO, da Silva CHL, de Souza RF. Behaviors and hygiene habits of complete denture wearers. Braz Dent J. 2013:21(3):247-52. 